\title{
Tick Bite
}

\section{Kene |sırı̆̆|}

\author{
Cansu Turan'(i D), Mustafa Hacımustafaoğlu'(iD) \\ ${ }^{1}$ Division of Pediatric Infectious Diseases, Department of Pediatrics, Uludag University School of Medicine, Bursa, Turkey
}

Question: What is the risk of Lyme disease after a tick bite? Should we give antibiotic prophylaxis to prevent? Tanju Meteris, MD

Cite this article as: Turan C, Hacımustafaoğlu M. Tick bite. J Pediatr Inf 2020;14(2):e87-e89.

\section{Answer (Cansu Turan, MD; Mustafa Hacımustafaoğlu, MD)}

Introduction and general information: Before answering these two questions, it will be useful to give some relevant information about the subject. Lyme disease is caused by the genus Borrelia (or Borreliella) spirochetes and is the most common group of diseases transmitted by the tick in the United States of America (USA) and Europe. Borrelia burgdorferi is common in the USA, however, in Europe and Asia, Borrelia afzelii and Borrelia garinii are more common. The disease is transmitted mainly by the bite of the Ixodes ricinus group ticks infected with Borrelia. Lyme disease, initially and the most commonly, involves the skin, and after can disseminate to non-skin disease (involving the joints, nervous system and heart). Ticks can also cause other diseases such as human granulocytic anaplasmosis, babesiosis, ehrliciosis, rocky mountain fever, tick-borne encephalitis, Crimean-Congo hemorrhagic fever (CCHF). The types of ticks that lead to these diseases may differ from each other. The prevalence of tick types in a region, the frequency of ticks carrying these agents, and the frequency of these diseases may vary in different the geographical locations. Ticks can transmit many other diseases apart from Lyme, including CCHF, anaplasmosis, ehrlichiosis, which can develope with fever and other findings. In Turkey, Ixodes ticks can transmit Lyme disease, and some other ticks (Hyalomma marginatum and Rhipicephalus bursa) can transmit the CCHF disease. Ticks transmitting Lyme disease are actively present in our country, especially in entire the Black Sea and Marmara regions. Ticks transmitting the CCHF are also seen in Central Anatolia and other regions as well as these regions. In this article, non-Lyme diseases will not be discussed. Tick bites can also cause allergic reactions within the first 24-48 hours at the site where the tick bite, and can also lead to secondary bacterial infections such as staphylococcus and streptococcus after impaired skin integrity.

There are three stages in the life cycles of the ticks: larvae, nymph and adult tick. Lyme disease can be transmitted by nymphs and adult ticks. Since nymphs are smaller, they are harder to see/detect in the body compared to adult ticks.

The risk of developing Lyme disease after a tick bite: Some factors are important in risk assessment for Lyme disease, if detectable after a tick bite. These are; presence of Ixodes type ticks (adults are usually hard-shelled, head and neck areas are more prominent), being in the hyperendemic region for this type of ticks, high B. burgdorferi infection rate of the ticks,

\section{Correspondence Address / Yazışma Adresi \\ Mustafa Hacımustafaoğlu \\ Uludağ Üniversitesi Tıp Fakültesi, \\ Çocuk Sağlığı ve Hastalıkları Anabilim Dalı, \\ Çocuk Enfeksiyon Hastalıkları Bilim Dalı, \\ Bursa-Türkiye \\ E-mail: mkemal@uludag.edu.tr}

Received: 26.06 .2020
Available Online Date: 04.08 .2020
@Copyright 2020 by Pediatric Infectious Diseases and Immunization Society. Available online at www.cocukenfeksiyon.org 
swollen appearance of the nymph or adult ticks due to feeding blood, presence of tick more than 36 hours in the skin. After the ticks bite, and after feeding and saturating blood for days, the tick leaves the body itself. Therefore, if the patient has a swollen, enlarged, and round-looking tick, or a similar tick has been seen at home, the risk of disease transmission is likely to be higher.

Ixodes ticks in the nymph stage are typically smaller and rounder (about $1 \mathrm{~mm}$ ). Adult lxodes ticks are about $3 \mathrm{~mm}$ in a blood-free (non-swollen) state and look flatter. However, the size of the ticks that swollen by feeding blood increase to $0.5-1$ $\mathrm{cm}$ and become more rounded. Blood-fed ticks hold firmly on the skin and are more difficult to remove. A small, round tick that walks on the skin surface or can be easily removed, has possibly not yet begun the feeding process, and therefore does not usually transmit Lyme disease. Feeding ticks release their saliva into the bite site as they absorb blood. However, animal studies have shown that spirochetes are not yet found in tick saliva in the first 48 hours after starting to suck blood. This is important in evaluating a patient with a tick-bite in terms of Lyme disease. Therefore, $B$. burgdorferi is rarely transmitted in the first 36-48 hours of tick adhesion. However, apart from $B$. burgdorferi, which is the cause of Lyme disease, other infection agents such as anaplasmosis, ehrlichiosis, babesiosis which are other zoonoses transmitted by ticks of the genus Ixodes; can be transmitted in the first 48 hous of tick bite, since they are found in the infective proportions of the tick salivary glands before the onset of blood feeding.

The tick needs to be infected with Borrelia spirochetes in order to infect Lyme disease to humans. In the USA, in the endemic regions in terms of Lyme disease, the rate of infection with B. burgdorferi in I. scapularis-type ticks was $20-30 \%$ in nymphs and $30-50 \%$ in adult ticks. Even in high endemic regions, after the bite of the I. scapularis tick (deer tick), developing of Lyme disease rate is about 1-3\%. In the USA, the annual incidence of Lyme disease in high endemic regions is reported as approximately 0.5 cases $/ 1000$ people. In our country, information about the tick types, Borrelia infection rate of ticks, Lyme disease development rates in humans after tick bite, and endemicity according to regions are clearly not been established.

In one study, in an endemic region Lyme disease developed in $3.7 \%$ (4 cases) of 105 people ( 109 bites) bitten by ticks. It was observed that the risk increased if the tick remained in the body for a long time. The risk of developing Lyme disease was 1.1\% $(1 / 94)$ in individuals with a tick retention time of $<72$ hours, whereas it was $20 \%(3 / 15)$ in those with $>72$ hours $(p=0.008)$. In this study, B. burgdorferi infection (DNA PCR positivity) was found in $14 \%$ of ticks.

In a patient presenting with a tick bite, the first job is to remove the tick carefully, and disinfect this area properly. When removing the tick, it should be removed without crushing it, without stressing it (not applying alcohol, olive oil, etc. on the tick). After removal, the skin should be disinfected, and the hands washed with soap and water. If the parts of the tick, such as the mouth, hose, and neck, remained on the skin after removing the tick, efforts should not be made to re-remove them completely. These remained small parts will spontaneously be excreted by the body later. Afterwards, follow-up of the patient is recommended in the first 48 hours in terms of local allergic reactions and subsequently for the signs of infection due to other agents. In terms of Lyme, it would be appropriate to follow up for a month in terms of erythema migrans, which is the finding of early localized disease in the tick-bite area, and to start treatment if the disease develops.

Antimicrobial prophylaxis after a tick bite: Erythema migrans, a typical clinical manifestation of Lyme disease (early localized disease), occurs in approximately $80 \%$ of patients infected with B. burgdorferi. Recognition and treatment of the disease at this early stage provides cure in almost all of the cases and prevents the development of early disseminate and late disease. The effectiveness of giving prophylactic antibiotics after a tick bite to prevent Lyme disease has been investigated in different studies. In three separate randomized, placebo-controlled studies, prophylactic amoxicillin given after a tick bite did not protect against the development of Lyme disease later. In the USA, the effect of a single dose of $200 \mathrm{mg}$ oral doxycycline in a hyper endemic region (Lyme incidence $0.05-0.1 \%$ ) for I. scapularis ticks and Lyme disease has been investigated. In this randomized, placebo-controlled, double-blind study, a single dose of $200 \mathrm{mg}$ oral doxycycline was given in 482 adolescents and adult patients, and cases were followed for 6 weeks. In this study, Lyme disease developed in $0.4 \%(1 / 235)$ patients in the doxycycline prophylaxis group, and $3.2 \%(8 / 247)$ in the placebo group ( $p<0.04)$. In this study, the efficacy of doxycycline was found to be $87 \%(95 \% \mathrm{Cl} ; 25-98)$, and it was calculated that an average of 40 people would need to give prophylaxis to prevent a Lyme case. However, doxycycline caused more side effects (such as nausea, vomiting) than placebo (30.1\% vs. $11.1 \%)$. In this study, the risk of Lyme disease was $0 \%(0 / 59)$ when the tick looked flat (with no blood-fed), and 9.9\% (8/81) in the presence of a blood-fed and swollen tick ( $p=0.02)$.

In the light of these findings, it is not appropriate to recommend prophylaxis in every tick bite. It would be appropriate to evaluate the patient individually and recommend prophylaxis in the presence of high risk factors. A single dose of doxycycline is recommended prophylactically for preventing Lyme disease in the presence of all of the following risk factors. These risk factors are: in the relevant region, the rate of infection of ticks with $B$. burgdorferi is high ( $\geq 20$ ), the tick is a blood-fed and swollen appearance, presence of adult or nymphal I. scapularis tick (deer tick), the tick has been in the body for at least $>36$ hours, prophylaxis can be initiated no later than 72 hours after removal of the tick and no contraindications for doxycycline. 
Prophylaxis dose in children is given as $4.4 \mathrm{mg} / \mathrm{kg} / \mathrm{dose}$, single dose with maximum $200 \mathrm{mg} /$ dose, orally

Before giving prophylaxis, the patient should be evaluated for the advantages and disadvantages of prophylaxis. The disadvantages of prophylaxis can be summarized as follows: In patients infected with $B$. burgdorferi, the disease can be fully treated and the transition to advanced late stages is prevented by giving antibiotics (doxycycline, amoxicillin, cefuroxime), and complete cure is achieved with the diagnosis of early localized disease in the presence of erythema migrans that develop within weeks after bite. The diagnosis and treatment of erythema migrans is easy. Thus, in many countries and regions where the disease is not frequent, unnecessary use of doxycycline will be prevented. As far as is known, no study is available on this subject, a single dose of doxycycline may alter the nature of the disease and then suppress the clinical diagnosis of Lyme disease. The ability to develop resistance to doxycycline may also be a disadvantage. Repetitive prophylaxis is applied to people who come with frequent tick bites in endemic tick regions where different tick types are frequently found; it may create some other problems such as economic, allergic and developing other resistant microbes. In addition, it may not be rational to give prophylaxis to each tick bite where if there are many types of ticks, and if the Borrelia infection rates of these ticks (B. burgdorferi, $B$. gardinii, B. afzelii) are unknown.

As a result; the risk of Lyme disease is expected to be higher in areas where the tick population that transmits Lyme disease (such as I. scapularis) is high, and the ticks are more likely to become infected with Borrelia, especially in cases where the tick fed or swollen with blood, the tick remained $>72$ hours in the body. In our country, Ixodes group ticks can be seen throughout Marmara and the entire Black Sea region, but their infection rate with Borrelia is not known. In addition, B. afzelli and B. gardinii infections are more common in the European region than B. burgdorferi. Such Borrelia species are less likely to cause extra-dermal disease (joint, facial paralysis, central nervous system and heart) findings, because they are less invasive than $B$. burgdorferi, which is more likely to be disseminated. The early localized of Lyme disease diagnosis (erythema migrans), which is only in the form of skin disease, is relatively easy to diagnose and the therapy is inexpensive and effective.

In conclusion, the answers our friend's question are:

a. Although we do not have detailed data for the risk of Lyme disease after a tick bite in our country, our country does not appear to be hyper-endemic in terms of tick related Lyme disease. In this context, the likelihood of developing Lyme disease after a tick bite can be considered low (possibly $1 \%$ and below).

b. In this context, it is not rational to give prophylactic doxycycline to each tick bite event to prevent Lyme disease. It is recommended that doxycycline prophylaxis can be given in the presence of all of the above-mentioned risk factors. In each case, the tick should be removed properly, and wound care should be performed. In addition, the patient should be monitored closely for the development of erythema migrans (early localized disease) during the first month of tick bite, and appropriate treatment should be given if it develops.

\section{References}

1. Hu L, Steere AC, Mittiy J (eds). https://www.uptodate.com/contents/ evaluation-of-a-tick-bite-for-possible-lyme-disease. Erişim tarihi: 25.06.2020. [CrossRef]

2. De Silva AM, Fikrig E. Growth and migration of Borrelia burgdorferi in Ixodes ticks during blood feeding. Am J Trop Med Hyg 1995;53:397-404. [CrossRef]

3. Shapiro ED. Borrelia burgdorferi (Lyme disease). Pediatr Rev 2014;35:500-9. [CrossRef]

4. Nadelman RB, Nowakowski J, Fish D, Falco RC, Freeman K, McKenna D, et al.; Tick Bite Study Group. Prophylaxis with single-dose doxycycline for the prevention of Lyme disease after an Ixodes scapularis tick bite. $N$ Engl J Med 2001;345:79-84. [CrossRef]

5. Sood SK, Salzman MB, Johnson BJ, Happ CM, Feig K, Carmody L, et al. Duration of tick attachment as a predictor of the risk of Lyme disease in an area in which Lyme disease is endemic. J Infect Dis 1997;175:996-9. [CrossRef]

6. Wormser GP, Dattwyler RJ, Shapiro ED, Halperin JJ, Steere AC, Klempner $M S$, et al. The clinical assessment, treatment, and prevention of lyme disease, human granulocytic anaplasmosis, and babesiosis: clinical practice guidelines by the Infectious Diseases Society of America. Clin Infect Dis 2006;43:1089-134. [CrossRef]

7. Piesman J, Lewengrub S, Rudzinska MA, Spielman A. Babesia microti: prolonged survival of salavarian piroplasms in nymphal Ixodes dammini. Exp Parasitol 1987;64:292-9. [CrossRef]

8. Warshafsky S, Lee DH, Francois LK, Nowakowski J, Nadelman RB, Wormser GP. Efficacy of antibiotic prophylaxis fort he prevention of Lyme disease: an updated systematic review and meta-analysis. J Antimicrob Chemother 2010;65:1137-44. [CrossRef]

9. Needham GR. Evaluation of five popular methods for tick removal. Pediatrics 1985;75:997-1002. [CrossRef]

10. Shapiro ED. Doxycycline for tick bites-not for everyone. N Engl J Med 2001;345:133-4. [CrossRef]

11. Steere $A C$, Sikand VK. The presenting manifestations of Lyme disease and the outcomes of treatment. N Engl J Med 2003;348:2472-4. [CrossRef]

12. Shapiro ED, Kaplan SL, Torchia MM (eds). Lyme disease: Clinical manifestations in children. https://www.uptodate.com/contents/lyme-disease-clinical-manifestations-in-children. Erişim tarihi: 25.06.2020. [CrossRef]

13. American Academy of Pediatrics. Lyme Disease. In: Red Book: 2018 Report of the Committee on Infectious Diseases. In: Kimberlin DW, Brady MT, Jackson MA, Long SS (eds). American Academy of Pediatrics, 2018:515-23. [CrossRef]

14. Shapiro ED, Gerber MA, Holabird NB, Berg AT, Feder HM Jr, Bell GL, et al. A controlled trial of antimicrobial prophylaxis for Lyme disease after deer-tick bites. N Engl J Med 1992;327:1769-73. [CrossRef]

15. Costello CM, Steere AC, Pinkerton RE, Feder HM Jr. A prospective study of tick bites in an endemic area for Lyme disease. J Infect Dis 1989;159:1369. [CrossRef]

16. Agre F, Schwartz R. The value of early treatment of deer tick bites for the prevention of Lyme disease. Am J Dis Child 1993;147:945-7. [CrossRef] 